\title{
PRECISIONES EN TORNO AL ORIENTALISMO DE LUCAS Y LAMEYER *
}

\author{
POR \\ ENRIQUE ARIAS ANGLÉS \\ Departamento de Historia del Arte \\ (C.E.H.) (C.S.I.C.)
}

La pintura orientalista española constituye aún un cierto vacío historiográfico en los estudios de nuestro arte del siglo XIX y principios del XX, a pesar de los intentos que se están haciendo ultimamente por abordarla. En esta línea están los trabajos llevados a cabo por Pilar Capelastegui ${ }^{1}$ y el que ésto escribe ${ }^{2}$, o el que recientemente ha realizado Eduardo Dizy que, a pesar de su intención y carácter divulgativos, constituye un amplio repertorio de 159 autores que cultivaron esta temática con sus correspondientes obras ${ }^{3}$, lo que lo convierte en un libro muy útil que viene a corroborar además, en rotundidad (ampliando la nómina de autores y obras), lo que afirmábamos en el primer estudio que a nuestro orientalismo pictórico dedicamos en $1988^{4}$ : la ineludible existencia de una pintura orientalista española —que no escuela - parangonable con las otras europeas de esta especialidad. Probada ya así, sobradamente, la existencia de una pintura orientalista española, cuyo gran volumen de producción transita todos los estilos que mediaron entre 1830 y 1930, se impone ahora —como fenómeno pictórico en sí con personalidad propia— abordar el análisis pormenorizado de la misma.

Ya hemos expuesto en otras ocasiones los inicios del orientalismo pictórico español, concretando en el romántico pintor Jenaro Pérez Villaamil (1807-1854) el arranque de nuestra pintura orientalista ${ }^{5}$. En dichos estudios expusimos como se plegó Pérez Villaamil, por española.

Este artículo es fruto del Proyecto de Investigación de la DGICYT № PB94-0059 La pintura orientalista

${ }^{1}$ Capelastegui, P.: El tema marroquí en la pintura española (1860-1927), Memoria de Licenciatura, Universidad Autónoma de Madrid, 1985 (inédita); idem: «Pintura de tema marroquí», Antiquaria, núm. 40, 1987, p. 24; idem: «Mariano Bertuchi y el paisaje marroquí», Goya, núm. 205-206, 1988, p. 68; idem: «El tema marroquí: Lameyer y Lucas», Archivo Español de Arte, t. LXV, núm. 257, 1992, p. 111.

2 Arias Anglés, E.: «La pintura orientalista», en Pintura orientalista española (1830-1930), Fundación Banco Exterior, Madrid, 1988, p. 23; idem: «La pintura orientalista española. Imágen de un tópico», en La imágen romántica del legado andalusí, El Legado Andalusí (Granada) - Lunwerg Editores S.A., Barcelona- Madrid, 1995, p. 47; idem: «Pérez Villaamil y los inicios del orientalismo en la pintura española», Archivo Español de Arte, t. LXXI, núm. 281, 1998, p. 1.

${ }^{3}$ Dizy Caso, E.: Los orientalistas de la escuela española, ACR Edition, París, 1997.

${ }^{4}$ Arias Anglés, E.: «La pintura orientalista», en Pintura orientalista española (1830-1930), Fundación Banco Exterior, Madrid, 1988, p. 32.

${ }^{5}$ Vid. obras de la nota 2. 
medio del influjo del pintor escocés David Roberts y de los grabados de otros artistas británicos del momento, a la incipiente iconografía orientalista internacional, realizando tanto cuadros alusivos a un orientalismo de carácter general, como a ese otro supuesto orientalismo español que el sujetivismo estético y emocionalismo románticos creía encontrar entre nosotros y que los románticos europeos convirtieron en símbolo de una pretendida síntesis cultural, concepto que, sustentado también por una especial iconografía, iba a proporcionar una imágen de lo español por demás falseada. Lo español aunaría de este modo el pintoresquismo a la poética de lo sublime, dentro de las aspiraciones del sujetivismo romántico. Contribuye así Villaamil a la definición de un historicismo nacional, que se va a producir entre nosotros, fundamentalmente, teniendo como base una reivindicación arqueológica en aras de la búsqueda de una identidad nacional ${ }^{6}$. Es por ello que nuestro artista se pliega a esta modalidad iconográfica del orientalismo europeo, entrando en su juego con numerosas representaciones al respecto.

Este orientalismo de tinte británico iniciado por Pérez Villaamil va a tener su continuación en el polifacético y controvertido pintor Eugenio Lucas Velázquez (1817-1870). Resulta paradójico (una vez más) que se tenga a Lucas como el introductor en la pintura romántica española de un orientalismo de corte delacroixiano, por dos cuadros enmarcables en tal estilo que tradicionalmente se le han atribuido (ya lo veremos luego), y se olvide que la mayor parte de su producción de carácter orientalista obedece, como buen número de sus paisajes, a la concepción británica que a ambos tipos de pintura imprimió Pérez Villaamil, amigo suyo y diez años mayor que él y de quien sabemos imitó o asimiló su estilo de pintura paisajística.

No son pocas las obras de carácter orientalistas que le conocemos a Lucas. Entre las recopiladas por Du Gué Trapier, Gaya Nuño y Arnaiz en los estudios que dedicaron al artista ${ }^{7}$, y alguna otra suelta por ahí, alcanzan aproximadamente algo más de una veintena. Casi todas ellas son de índole meramente paisajístico; paisajes de tipo oriental sin el menor atisbo de relación alguna con la realidad. Pura fantasía del artista, quizá ayudada por la contemplación de algún grabado u otra obra semejante de algún otro pintor. Esta forma de abordar el tema orientalista nos pone de manifiesto cómo Lucas se planteaba su pintura de forma bien diferente a la de Pérez Villaamil. Su romanticismo no posee una base intelectual o teórica, sino meramente intuitiva. Y también, por su sensibilidad más próxima a lo popular, y a pesar de su calidad pictórica, sus obras rara vez alcanzan el refinado halo de poesía y estilización que poseen las de Pérez Villaamil. El extraño encanto de las obras de Lucas, en general, radica en que une una maestría pictórica, colorística, innata a unas formas y un tratamiento de los temas un tanto burdo, próximo, como decimos, a una mentalidad de carácter más primario y popular (con sus maravillosas excepciones, que las hay, por supuesto). Pintura la suya, al fin y al cabo, de veta brava (como se la ha calificado) en todos los sentidos, en la técnica y en la temática, pero por ello también, generalmente, con más garra y fuerza expresiva que la de Pérez Villaamil, debido a su mayor riqueza de empaste, soltura de pincelada y viveza de colorido.

Como decimos, la mayoría de la producción orientalista de Lucas se enmarcaría en la vertiente iconográfica de paisajes orientales. No existe en Lucas esa inquietud, ese proyecto, de reivindicación arqueológica en consonancia con el pensamiento historicista y ecléctico europeo que caracterizó al arte de Pérez Villaamil, cuando aborda una temática semejante a

\footnotetext{
"Henares Cuéllar, I.: «Viaje iniciático y utopía: estética e historia en el romanticismo», en La imágen romántica del legado andalusí, El Legado Andalusí (Granada) - Lunwerg Editores S.A., Barcelona- Madrid, 1995, pp. 22 a 27.

7 Du Gué Trapier, E.: Eugenio Lucas y Padilla, New York, 1940; Gaya Nuño, J. A.: Eugenio Lucas, Barcelona, 1948; Arnaiz, J. M.: Eugenio Lucas. Su vida y su obra, Madrid, 1981.
} 
la de este pintor. Sus ruinas, sus representaciones de monumentos islámicos, obedecen a una concepción eminentemente fantasiosa y decorativa sin el menor ánimo de acercamiento a una realidad evocadora de determinadas posiciones intelectuales que buscaran — consciente o intuitivamente- la definición de un historicismo nacional. Quizá la única obra orientalizante de Lucas enmarcable, en cierto sentido, en esta tendencia sería la que Arnaiz titula Muros de la Alhambra (Fundación Lázaro Galdiano) ${ }^{8}$, y sólo porque se trata, a juicio de Du Gué Trapier, de una copia de The Tower of Comares de David Roberts, publicado en The Tourist in Spain ${ }^{9}$. Pero igualmente corta es la nómina por lo que respecta a monumentos de carácter no islámico.

Así, dentro de esta noción eminentemente paisajística con fantásticas arquitecturas de tipo islámico y anécdotas de personajillos de tipo oriental, tenemos los óleos titulados Puerto oriental (fig. 1), de 1848, y Paisaje oriental (fig. 2), de $18566^{10}$, ambos firmados y en colecciones particulares, en los que una abigarrada multitud de personajes árabes se halla acampada a los piés de unas monumentales ruinas de carácter musulmán situadas a orillas del mar, con sus correspondientes veleros; composiciones ambas muy similares y que se inspiran claramente en la estructura del óleo de Pérez Villaamil conocido como Fragmento de fortificación árabe del Museo Nacional de Bellas Artes de Buenos Aires (fig. 3) ${ }^{11}$, de 1838, que, a su vez, el propio Pérez Villaamil reprodujo casi literalmente en la estampa I del cuaderno $1^{\circ}$ del tomo I de su España Artística y Monumental, tema que, al parecer de Salas, se halla inspirado en David Roberts ${ }^{12}$. La diferencia radica en que en el cuadro y la litografía de Pérez Villamil, a pesar de obedecer ambos a una concepción eminentemente fantasiosa, colocando la Puerta del Sol de Toledo a orillas de una playa mediterránea, el monumento está tomado, con algunas modificaciones, del natural, mientras que las correspondientes arquitecturas que equivaldrían a ésa en los dos cuadros de Lucas son creaciones de pura inventiva. Citaremos aquí también, por ser pareja del antes mencionado Puerto oriental, el óleo titulado por Gaya Nuño y Arnaiz Ruinas con figuras árabes (colección particular) ${ }^{13}$, firmado y fechado en 1848, donde, dentro de esta acepción paisajística, Lucas cultiva un tema típico de la pintura orientalista, el del desierto, aunando en la representación las dos vertientes características de esta iconografía, la de la caravana y el de las ruinas de la Antigüedad enmarcadas por esas grandes soledades; sin embargo, el modelo de ruinas clásicas que utiliza el artista en el cuadro está desfasado en cuanto a los conocimientos sobre el arte clásico que ya sobradamente se tenían a mediados del siglo XIX, pareciendo estar inspiradas dichas arquitecturas, así como su colocación, en modelos de algún cuadro o grabado de otro siglo anterior, lo que le proporciona un sabor añejo a la composición, alejándola un tanto de las del mismo tipo realizadas por Pérez Villaamil. Citaremos también, dentro de esta temática, el pequeño boceto a la acuarela y tempera mencionado por Du Gué Trapier con el titulo de Alto en el desierto ${ }^{14}$, firmado y fechado en 1868 y que pertenecía las galerias Demotte.

${ }^{8}$ Arnaiz, J. M.: Op. cit. nota 7, p. 360, núm. 137.

${ }^{9}$ Du Gué Trapier, E.: Op. cit. nota 7, p. 14.

${ }^{10}$ Gaya Nuño, J. A.: Op. cit. nota 7, p. 10 y fig. 4 (con el título de Ruinas con figuras árabes); Arnaiz, J. M.: Op. cit. nota 7, p. 14, ilust. 3 (con el título de Puerto oriental) y p. 296, núm. 19 (con el título de Ruinas con figuras árabes); VV. AA.: Cien años de pintura en España y Portugal (1830-1930), Antiquaria, Madrid, 1990, t. 4, p. 389.

1 Arias Anglés, E.: El paisajista romántico Jenaro Pérez Villaamil, CSIC, Madrid, 1986, p. 226, núm. 72, fig. 39 .

${ }^{12}$ Salas, X. de: «Varias notas sobre Jenaro Pérez Villaamil», Archivo Español de Arte, t, XXXI, 1958, p. 282.

${ }^{13}$ Gaya Nuño, J. A.: Op. cit. nota 7, p. 10, fig. 3; Arnaiz, J. M.: Op. cit. nota 7, p. 296, núm. 20.

${ }^{14}$ Du Gué Trapier, E.: Op. cit. nota 7, p. 30. 

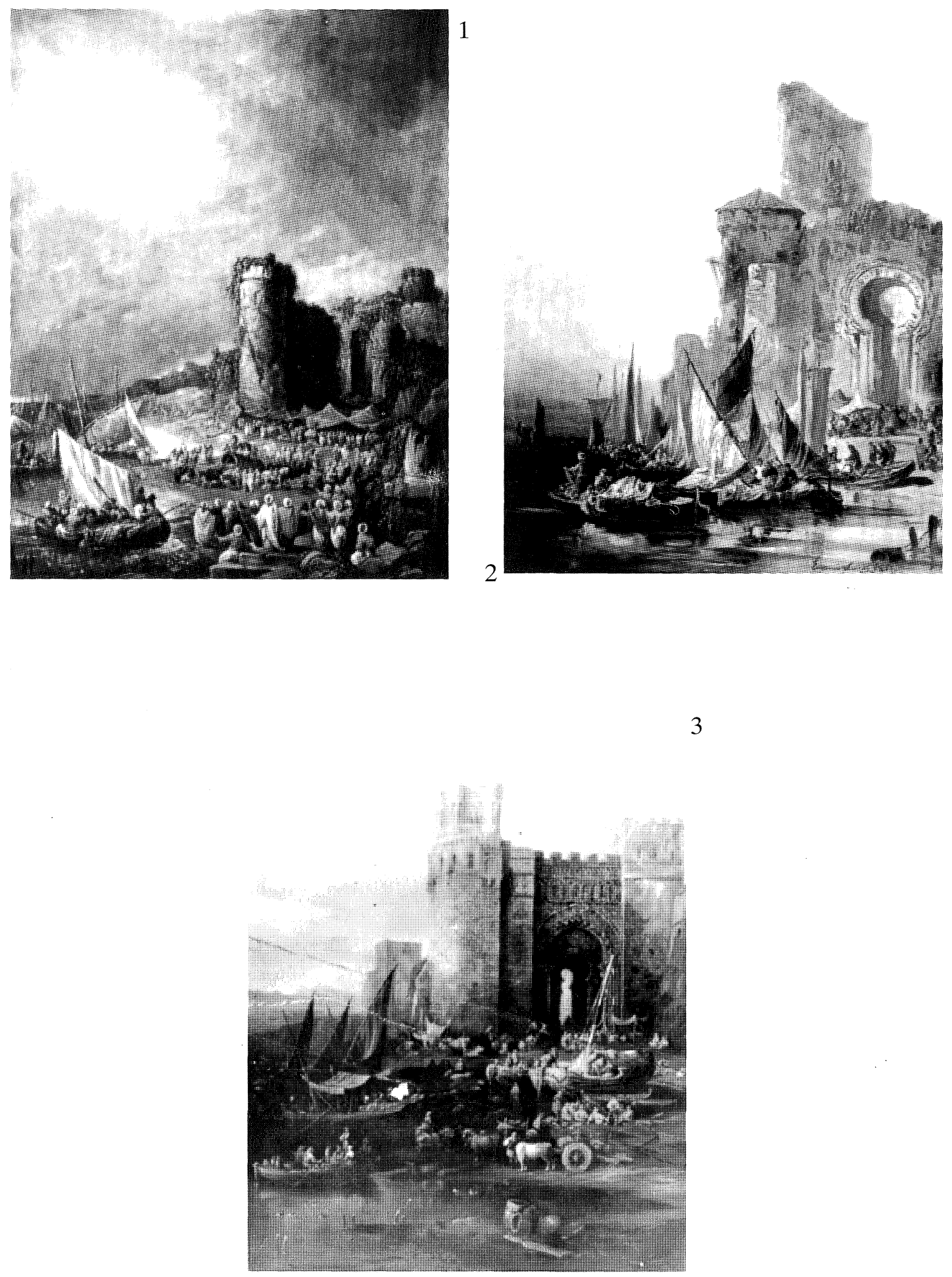

Figura 1. Eugenio Lucas. Puerto oriental. Colección particular.

Figura 2. Eugenio Lucas. Paisaje oriental. Colección particular.

Figura 3. Jenaro Pérez Villaamil. Fragmento de fortificación árabe. Museo Nacional de Bellas Artes. Buenos Aires. 
Igualmente, dentro de esta concepción eminentemente paisajística, aún hay que situar otro par de óleos titulados Costa mora al atardecer y Costa mora bajo la luna (ambos en el Museo de Arte de Ponce, Puerto Rico) ${ }^{15}$, firmados y fechados en 1860. Estos óleos -bellos efectos de luz sobre paisajes costeros con figuras orientales y apuntes de arquitecturas en las lejanías y que forman pareja- entran también dentro de la idea y tratamiento que Pérez Villaamil daba a este tipo de representaciones, aún estando fechados seis años después de la muerte de éste, si bien con los rasgos propios de la personalidad de Lucas en cuanto a la ténica.

Las mismas características que estos anteriores nos muestran los gouaches titulados Pesqueros en un puerto de África del norte y Escena de puerto de África del norte (ambos en colección privada) ${ }^{16}$, que forman pareja, estando firmados y fechados en 1859 y dedicados a su amigo D. Ángel Pozas; obras a las que ya Du Gué Trapier aludía como posible testimonio de una incierta estancia de Lucas en Marruecos, que ni ella misma creía muy probable ante tan débil sugerencia ${ }^{17}$ y que, en parecidos términos, son también citadas por Arnaiz ${ }^{18}$. En realidad, son representaciones de fantasía, convencionales, al modo de las ya vistas anteriormente, resultando inapropiada la referencia que Du Gué Trapier hace a Ceuta en virtud de la torre en ruinas de probable estilo manuelino que aparece en una de ellas ${ }^{19}$, siendo, por el contrario, acertada y significativa la alusión que hace a las reminiscencias que poseen de la escuela inglesa de paisaje ${ }^{20}$, que nos remiten claramente al influjo de Pérez Villaamil. Muy similares a éstos eran, a decir de Du Gué Trapier, los dos esbozos de semejante temática que pertenecieron a la colección Bosch, uno de ellos firmado también en $1859^{21}$, e igualmente, a decir también de dicha autora, guarda una cierta semejanza compositiva con todos éstos un pequeño óleo que perteneció a la colección Randall Smith de New York ${ }^{22}$. Incluimos aquí, por poseer características compositivas parecidas, según la breve descripción que de ella da Du Gué Trapier, la acuarela fechada en 1860 que lleva una inscripción del autor dedicándosela a Don Patricio Sobrade como parte del pago de una deuda y que estuvo en las galerías Demotte, donde una gran torre domina la escena, con grupos de moros discurriendo al primer término ${ }^{23}$.

Dentro de estas características, hemos de citar también los gouaches Moros en un paisaje montañoso y Caravana en un paisaje con tormenta (Banco de España, Madrid) ${ }^{24}$, obras sin firma ni fecha, en las que son también inconfundibles los rasgos técnicos de Lucas, en especial en el tratamiento de las figuras, que parecen haber sido añadidas sobre unos paisajes realizados previamente mediante el método o sistema del pintor inglés de finales del siglo XVIII Alexander Cozens, o sea, a base de manchas arbitrarias de color a las que la imaginación del artista acababa dando forma definitiva con el pincel, sistema que sabemos

${ }^{15}$ Arnaiz, J. M.: Op. cit. nota 7, p. 460, núms. 318 y 319.

${ }^{16}$ Du Gué Trapier, E.: Op. cit. nota 7, pp. 28 y 29, lám. XIX; Gaya Nuño, J. A.: Op. cit. nota 7, pp. 21 y 45; Catálago Sala de Arte y Subastas Durán, núm. 88, t. II, mayo de 1977, p. 202, núms. 250 y 251; Arnaiz, J. M.: Op. cit. nota 7, los reproduce con los títulos de La vuelta de la pesca (p. 151, ilust. 152) y Barcos y ruinas (p. 154, ilust. 159).

${ }^{17}$ Du Gué Trapier, E.: Op. cit. nota 7, pp. 28 y 31.

${ }_{18}$ Arnaiz, J. M.: Op. cit. nota 7, p. 29.

${ }^{19}$ Du Gué Trapier, E.: Op. cit. nota 7, pp. 28 y 29.

${ }^{20}$ Ibidem, p. 29.

${ }^{21}$ Ibidem.

${ }^{22}$ Ibidem.

${ }^{23}$ Ibidem, p. 30.

${ }^{24}$ Arias Anglés, E.: «La pintura romántica de paisaje en España», en Pinturas de paisaje del romanticismo español, Fundación Banco Exterior, Madrid, 1985, pp. 98 a 101, núms. 40 y 41. 
practicaron tanto Pèrez Villaamil como Lucas ${ }^{25}$. Son estos gouaches, al igual que los anteriores, obras también realizadas dentro de las directrices de la pintura de Pérez Villaamil, razón por la que, en algún momento, han presentado dudas de atribución a ciertos autores, y eso a pesar de llevar ambos gouaches al dorso una certificación de Gómez Moreno atribuyendo indudablemente su autoría a Lucas ${ }^{26}$, certificación que suscribimos plenamente.

Y aún citaremos dentro de esta vertiente paisajística — sin poder saber si entra dentro del influjo de Pérez Villaamil- el óleo que perteneció a las galerías Demotte descrito por Du Gué Trapier ${ }^{27}$ y recogido por Gaya Nuño con el título de Cabalgada mora ${ }^{28}$, representado una someramente esbozada cabalgada de jinetes moros a orillas del mar.

Esta asimilación o imitación estilística por parte de Lucas del arte de su amigo el romántico gallego, no ha dejado de presentar problemas a la hora de atribuirle ciertas obras a uno u otro pintor, como acabamos de ver. Así, dentro de estas composiciones orientalistas de Lucas ejecutadas bajo el influjo de las de Pérez Villaamil, tenemos dos óleos, que se conservan en el Museo de Bellas Artes de Castellón, sin firma ni fecha de ejecución, que ya Gaya Nuño atribuyó a Lucas, calificándolos como «dos preciosos, extremadamente cautivadores, "Puertos orientales", de Eugenio Lucas, en su manera más próxima a Pérez Villaamil» ${ }^{29}$ y que fueron posteriormente incluidos en el catálogo de las obras de Lucas que hizo Arnaiz con los títulos de Puerto oriental con carreta (fig. 4) y Puerto oriental con ruinas ${ }^{30}$ (fig. 5). El problema estriba en que se trata de dos copias - con algunas variantes en el encuadre, composición de los grupos de personajes y proporciones de las arquitecturas- de las obras de Pérez Villamil tituladas Fragmento de fortificación árabe ${ }^{31}$ (fig. 3), antes citada, y Caravana a la vista de Tiro ${ }^{32}$ (fig. 6), ambas perfectamente documentadas y catalogadas por el que esto escribe. Resulta extraño que Lucas hiciese copias casi literales de obras de Pérez Villaamil, pues aunque fuese diez años menor en edad que este último, no nos consta que hubiese sido discípulo suyo - conocemos copias de obras de Pérez Villaamil hechas por sus alumnos ${ }^{33}$-, sino amigo, y más cuando, en la fecha en que firma el segundo de esos cuadros el gallego - 1846-, Lucas tenía treinta años, suponiéndose que para entonces sería ya un artista formado. Podría objetarse a ésto el que, en el Museo Lázaro Galdiano, se conservan dos cuadros idénticos de Lucas y Pérez Villaamil bajo el común tema y título de Castillo roquero ${ }^{34}$. Pero se da el caso de que, al parecer, no se trata de una copia por parte del primero de un cuadro original del segundo, sino que ambas obras son producto de una especie de competición amistosa ${ }^{35}$ que mantuvieron durante un tiempo ambos artistas, tanto siguiendo el sistema Cozens para la

${ }^{25}$ Salas, X. de: Op. cit. nota 12, pp. 273 a 277; Arias Anglés, E.: Op. cit. nota 11, pp. 190 y 191.

${ }^{26}$ Vid. nota 24.

${ }^{27}$ Du Gué trapier, E.: Op. cit. nota 7, p. 30.

${ }^{28}$ Gaya Nuño, J. A.: Op. cit. nota 7, p. 21 (lo cita nuevamente en la p. 45 con el título de Escena de moros).

${ }^{29}$ Gaya Nuño, J. A.: Historia y guía de los museos de España, Espasa-Calpe, Madrid, 1968 (segunda edición), p. 231

${ }^{30}$ Arnaiz, J. M.: Op. cit. nota 7, p. 572, núms. 493 y 494.

${ }^{31}$ Vid. nota 11.

${ }^{32}$ Arias Anglés, E.: Op. cit. nota 11, p. 247, núm. 145.

${ }^{33}$ Ejemplo de ello serían las que de José Brugada, discípulo de Villaamil, se conservan en la Fundación Santamarca de Madrid (Arias Anglés, E.: «José Brugada, pintor paisajista y de interiores», Goya, núm. 154, 1980, p. 206).

${ }^{34}$ Arias Anglés, E.: Op. cit. nota 11, pp. 259 y 260, núm. 174; Arnaiz, J. M.: Op. cit. nota 7, p. 358, núm. 134 (con el título de El torreón).

${ }^{35}$ Camón Aznar, J.: Guía del Museo Lázaro Galdiano, Madrid, 1973, p. 73; Urgorri Casado, F.: «Villaamil y Lucas: torneo de pinceles», en Pintores ferrolanos, Excma. Diputación Provincial de La Coruña, La Coruña, 1980, p. 49; Arias Anglés, E.: Op. cit. nota 11, p. 190. 


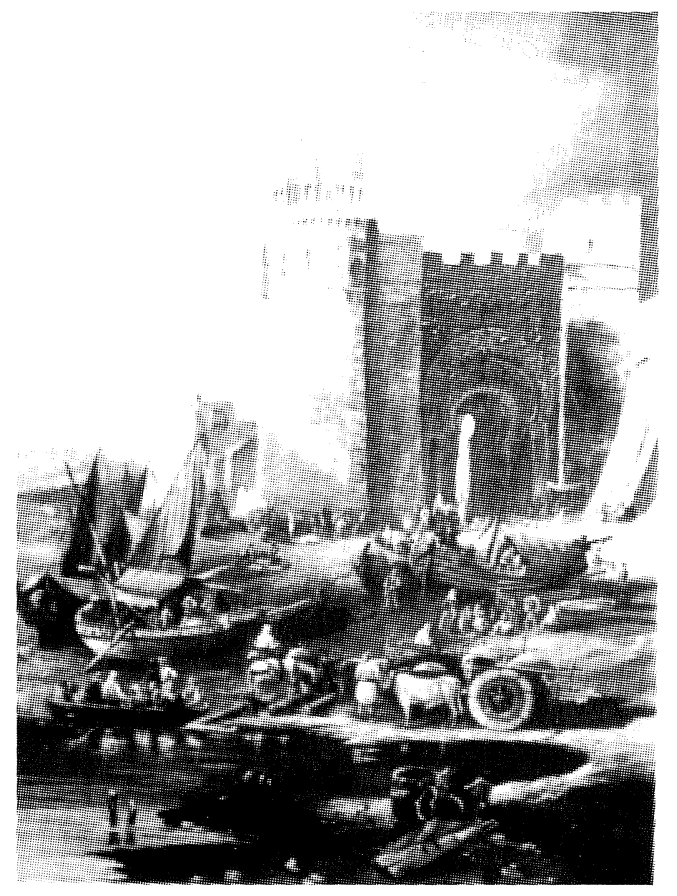

4

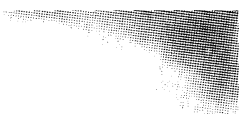

5

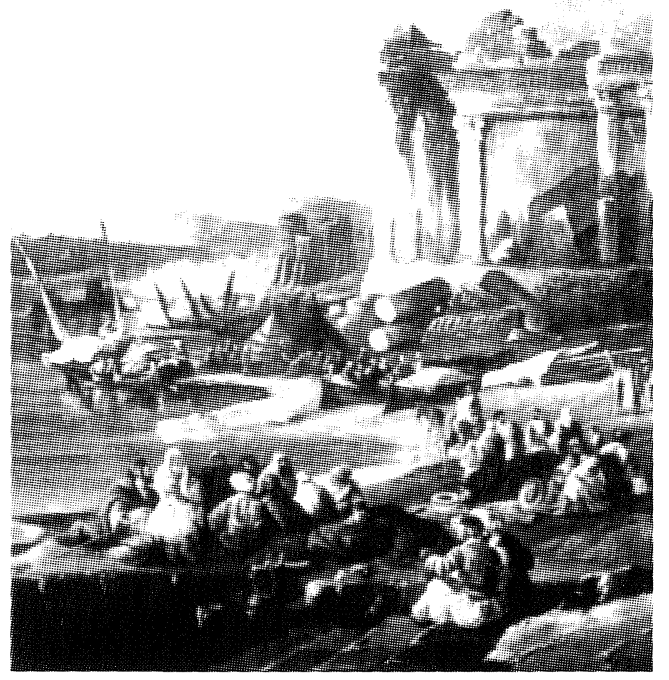

6

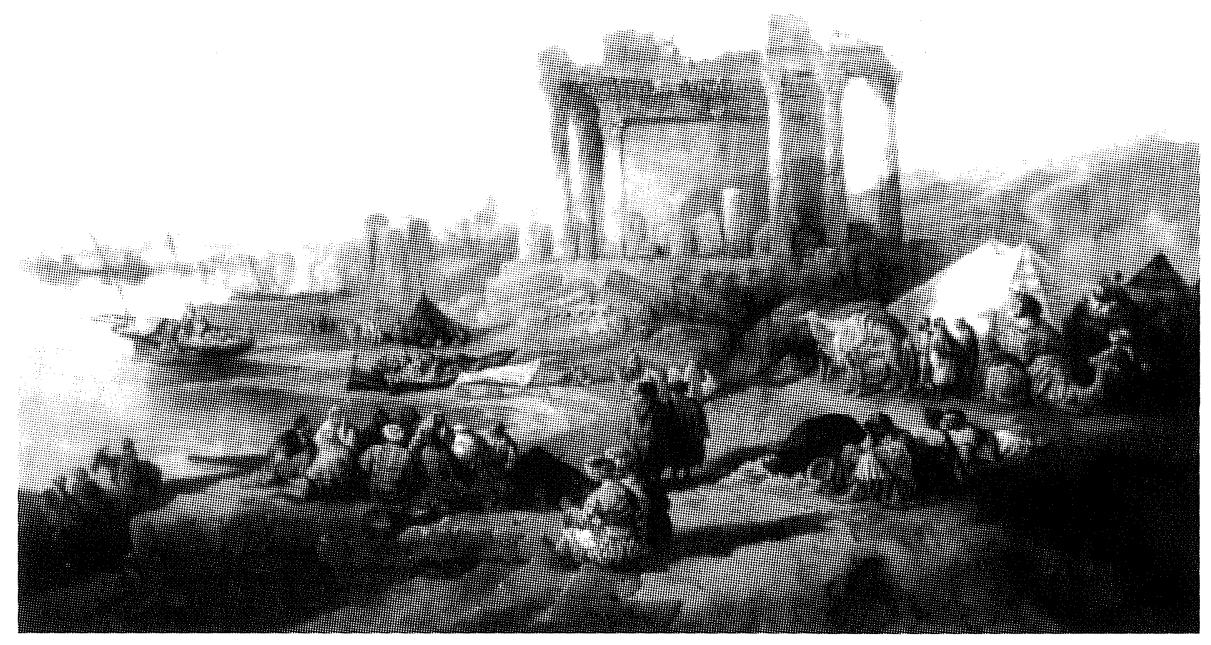

Figura 4. Tradicionalmente atribuido a Eugenio Lucas. Puerto oriental con carreta. Museo de Bellas Artes. Castellón de la Plana.

Figura 5. Tradicionalmente atribuido a Eugenio Lucas. Puerto oriental con ruinas. Museo de Bellas Artes. Castellón de la Plana.

Figura 6. Jenaro Pérez Villaamil. Caravana a la vista de Tiro. Fundación Santa Marca. Madrid. 
la acuarela, antes citado, como quizá copiando ambos directamente de un mismo grabado, como parecer ser el caso de estos dos casi idénticos cuadros, que difieren sólo, practicamente, en el colorido y algún nimio detalle en celajes, proporciones y lejanías, propios de la visión personal que cada artista tuvo del modelo. El excesivo nerviosismo y rapidez de la factura en ambas obras, su aspecto de mancha rápida, de boceto, avalan este sentido de competición a que hemos aludido, así como la dedicatoria que conserva el cuadro de Pérez Villaamil: «Villaamil á Lucas. 11 de Octubre 1853, en media hora dada al amigo y al arte». Sin embargo, no parece ser este el caso de las dos obras orientalistas que tratamos, cuya factura mucho más acabada y esa cierta libertad de interpretación de los originales, por parte del copista, parecen corroborarlo. Pero además, la dura factura de estas copias, en relación con las técnicas más sueltas generalmente empleadas por Lucas y Pérez Villaamil, alejan también la posibilidad de que se traten tanto de copias libres por parte del primero, como de versiones de sus propias obras por parte del segundo. En una palabra, todo ello nos lleva a mantener serias y fundadas dudas sobre la atribución a Lucas de ambos cuadros, pensando que más bien pudieron ser copiados por algún discípulo avanzado de Pérez Villaamil —como conocemos en otros casos-, que realizadas, como ya hemos dicho, por Lucas o el mismo Pérez Villaamil.

Más radical aún - por plenamente seguro- es el cambio de atribución que vamos a realizar de otra de estas obras de carácter villaamilesco de Lucas. Nos referimos a la que se conserva en la Fundación Lázaro Galdiano bajo el título de $\operatorname{Los~cruzados}^{36}$ (fig. 7), óleo sobre lienzo de $0,510 \times 0,660 \mathrm{~m}$., sin firma ni fecha de ejecución y que, por su tamaño y aspecto de mancha rápida de nerviosa factura —además de por otras razones que luego expondremos-, se trata muy probablemente de un boceto. No sabemos que motivos llevarían a darle el título por el que lo conocemos, pues, en principio, una visión del tema induciría a pensar en el más impersonal y menos comprometido del asedio de una ciudad o castillo que en el más rebuscado de Los cruzados. Cabe también la posibilidad de que ẹl cuadro lo trajera ya desde su lugar de procedencia al ser adquirido; pero, desde luego, el que el cuadro se conserve con dicho título, precisamente, no deja de ser significativo ni de tener cierto peso específico para lo que pretendemos, como luego veremos. Mas, si estamos plenamente de acuerdo con el título, en lo que desde luego no lo estamos es en la atribución a Lucas de esta obra, por mucho que su aspecto abocetado indujera a ello.

Ya García-Herraiz, en 1973, comentando este cuadro nos expresa sus acertadas dudas al respecto: «¿Cómo no dudar a la vista y fácil comparación con otros de esta exposición, de que el cuadrito de "Las Cruzadas", de la Fundación Lázaro Galdiano, con su nerviosa y afilada factura, sus tintas aplicadas con toque de dibujante fácil, no nos recuerdan más a Pérez Villaamil que al artista a que viene siendo atribuido? Bien es verdad que este cuadro, como muchos otros atribuidos a Eugenio Lucas, ha dejado dubitativos a más de un observador y entre ellos a Elizabeth du Gué Trapier» ${ }^{37}$. En efecto, esta investigadora norteamericana se había referido, en 1940, al cuadro que tratamos en los siguientes e indecisos términos: “Los Cruzados en Jerusalem” (Colección Lázaro) parece ser de Lucas. Aunque un asunto semejante por Pérez Villaamil fue exhibido en 1857 en Sevilla, la descripción contemporánea no corresponde totalmente con este impresionista boceto...» ${ }^{38}$. Esta vacilación en la atribución a Lucas de la obra y sospechosa, a la vez que significativa, alusión al cuadro de semejante tema de Pérez Villaamil, parece indicarnos que la autora hubiera querido de buena gana

\footnotetext{
${ }^{36}$ Se la cita también con otros títulos similares a éste, como Las Cruzadas o Los cruzados en Jerusalem, con los que indistintamente nos referiremos a continuación al mismo.

${ }^{37}$ García-Herraiz, E.: «En torno a Eugenio Lucas: a propósito de una exposición», Goya, núm. 114, 1973, p. 349.

${ }^{38}$ Du Gué Trapier, E.: Op. cit. nota 7, p. 15.
} 
atribuir el cuadro (al que ya menciona como «boceto») a este último maestro, no decidiéndola totalmente el hecho de que la citada descripción no coincide plenamente con la del boceto de la Fundación Lázaro Galdiano. Pudiera ser, sin embargo, que la descripción fuese asaz superficial, quizá referida sólo a la ambigüedad de un título, pudiera ser también que la descripción de una obra acabada no coincidiera integralmente con su boceto, o pudiera ser igualmente que se tratara de otro cuadro de Pérez Villaamil también con asunto sobre las Cruzadas, como luego veremos. Pues bien, a pesar de estas razonables dudas, por Lucas se le tiene en la Fundación Lázaro Galdiano y como cuadro de tal autor lo publica Arnaiz, en 1981, en el catálogo que de sus obras hizo ${ }^{39}$, manteniendo aún más recientemente, en 1997, tal atribución también Dizy ${ }^{40}$. Y, sin embargo, el cuadro es de Pérez Villaamil, como lo han sido otros varios catalogados como de Lucas ${ }^{41}$. Ni tan siquiera su aspecto bocetístico puede constituirse en argumento definitivo, pues, aunque Pérez Villaamil no utilizara una técnica tan de veta brava como la de Lucas (que, a veces, tampoco es tan brava), no es el primer cuadro del gallego que conocemos con este carácter abocetado y manchista, de rápida y nerviosa factura. Ya que sabemos que Pérez Villaamil realizaba y guardaba bocetos de obras que, por su acierto temático-artístico y consiguiente buena venta en el mercado, podía repetir, posteriormente, en réplicas o versiones de mayor o menor exactitud y calidad, según los casos ${ }^{42}$. Serían bastantes los ejemplos que podríamos citar de estas réplicas de sus obras, pero creemos de lo más significativo el caso de los cuadros titulados Una corrida de toros en la plaza de un pueblo y La Casa del rey Don Pedro en Alcalá de Henares, de los que conocemos dos muy exactas y acabadas versiones de cada uno, además de los citados bocetos recordatorios y preparatorios de los mismos ${ }^{43}$, todos ellos en colecciones particulares. En los cuadros definitivos, dentro de la generalmente suelta factura que utilizaba Pérez Villaamil, se acusa el perfecto acabado de las arquitecturas y el deslinde individualizado de los personajes dentro de los abigarrados conjuntos en que los agrupa; mientras que en los bocetos, los volumenes arquitectónicos están someramente apuntados en sus detalles y los grupos de personajes constituidos por confusas manchas de color, de cuya heterogeneidad se sugiere, aquí y allá, sucintamente, con nervioso y empastado trazo, la escueta individualidad de algunos personajillos. Dentro de esta concepción bocetística de Pérez Villaamil está el cuadro de la Fundación Lázaro que tratamos, respondiendo plenamente tanto a su estilo como al procedimiento que utilizaba en este tipo de pinturas, como bien sospechaba García-Herraiz.

Pero, además del análisis técnico, también el formal aporta nuevos y concluyentes datos al respecto. En primer lugar, la estructura compositiva de la obra es muy similar a la del cuadro de Pérez Villaamil que titulamos Las gargantas de las Alpujarras ${ }^{44}$ (fig. 8), que se conserva en la Fundación Santamarca de Madrid: en ambas obras, laderas rocosas a uno y otro lado delimitan una quebrada garganta central que desemboca, hacia el fondo del cuadro,

\footnotetext{
${ }^{39}$ Arnaiz, J. M.: Op. cit. nota 7, p. 504, núm. 390.

${ }^{40}$ Dizy Caso, E.: Op. cit. nota 3, p. 157 (con el título de Escena marroquí).

${ }^{41}$ Tal sería el caso del cuadro de Pérez Villaamil publicado por nosotros con el título de Paisaje montañoso (¿Los Picos de Europa?) (Arias Anglés, E.: Op. cit. nota 11, p. 264, núm. 187), que anteriormente fue catalogado por Arnaiz como de Lucas con el título de El desfiladero (Arnaiz, J. M.: Op. cit. nota 7, pp. 10 y 462, núm. 325).

${ }^{42}$ En efecto, según se desprende de las anotaciones que de sus cuadros hizo el pintor en el Diario que llevó durante su estancia en Francia y Bélgica desde 1840 a 1844 (Arias Anglés, E.: Op. cit. nota 11, p. 537, núm. 287), Pérez Villaamil repetía los temas que consideraba de fácil venta; lo que nos confirma la aparición, en las colecciones privadas y el mercado de arte, de obras idénticas (con ligeras variantes) del artista.

${ }^{43}$ Arias Anglés, E.: «Jenaro Pérez Villaamil», en De la Edad Media al Romanticismo, CAYLUS Anticuario S.A., Madrid, 1993, pp. 214 a 217.

${ }^{44}$ Arias Anglés, E.: Op. cit. nota 11, p. 250, núm. 152.
} 
en un promontorio sobre el que se contempla la silueta a contraluz de una ciudad, en un caso, y de un castillo, en el otro, iluminados por los últimos rayos de una romántica, espectacular e idéntica puesta de sol que colorea de dorados tonos a los celajes, arquitecturas y orografía circundante. Por otro lado, si comparamos el promontorio montañoso coronado por la ciudad amurallada (que sin duda quiere ser Jerusalem) del cuadro de Los cruzados que estamos tratando, con el que, igualmente coronado por semejante ciudad (Jerusalem), aparece al fondo de otro cuadro de Pérez Villaamil que se conserva en el Patrimonio Nacional con el título de Ruinas en las inmediaciones de Jerusalem ${ }^{45}$ (fig. 9) -también de semejante estructura compositiva-, nos damos de inmediato cuenta de la práctica igualdad entre uno y otro; las pequeñas diferencias que se pueden establecer vienen determinadas, fundamentalmente, por el carácter de boceto que tiene el de Los cruzados frente al de obra acabada que posee el del Patrimonio Nacional, como podemos ver - por acusarse más en los detalles- entre las dos representaciones de Jerusalem que coronan dichos promontorios, estando más precisadas en este último cuadro las murallas y siluetas de edificios, las torres, minaretes y cúpulas, mientras que en el primero aparecen someramente apuntadas a causa de su carácter abocetado, pero sin dejar de guardar por ello gran semejanza ambas representaciones entre sí.

Pero aún hay más. Pasando ahora al análisis histórico, nos encontramos con que Pérez Villaamil trató el tema de los cruzados y Jerusalem, en títulos como Jerusalem ${ }^{46}$, La toma de Jerusalem por Godofredo de Bouillon —o La toma de Jerusalem por los cruzados- ${ }^{47} \mathrm{y}$ Los cruzados descubriendo la ciudad de Jerusalem ${ }^{48}$. No conocemos hoy día ninguna de estas obras, más que por las referencias literarias y críticas que nos han llegado, lo que hace que incluyamos la primera de ellas sólo porque, en virtud de su título, pudiera tener alguna relación con el asunto de las Cruzadas; mientras que, por lo que respecta a las dos siguientes - de temáticas tan semejantes-, al no tener de ambas referencias cronológicas de críticas o exposiciones - sólo sabemos que La toma de Jerusalem por los cruzados se exhibió en la exposición de la Academia de San Fernando en $1850^{49}$ - que nos las pudiesen identificar o diversificar claramente, tenemos que pensar, en principio, por virtud de sus títulos, que se trate de dos obras diferentes, una representando el «descubrimiento» de Jerusalem por los cruzados y la otra el momento de la «toma» de la ciudad por los mismos, pudiendo quizá ser ésta última la obra a que se refiere Du Gué Trapier como expuesta en Sevilla en 1857, tres años después de la muerte de Pérez Villaamil. Sea como fuere, lo que nos importa en relación con el asunto que tratamos es el hecho de que Pérez Villaamil pintó un cuadro con el clarísimo asunto de Los cruzados descubriendo la ciudad de Jerusalem, cuadro que perteneció a la colección que los duques de Montpensier tuvieron en el palacio de San Telmo de Sevilla, como así consta en el catálogo de dicha colección que se editó en $1866^{50}$. Y da la enorme casualidad de que el cuadro atribuido a Lucas en la Fundación Lázaro Galdiano, bajo el significativo título de Los cruzados, representa claramente a los cruzados exaltados a la vista de la ciudad de Jerusalem, o sea que coincide plenamente con el título del cuadro de Pérez Villaamil que estuvo en la colección de los duques de Montpensier: Los cruzados descubrien-

${ }^{45}$ Ibidem, p. 246, núm. 143.

${ }^{46}$ Ossorio y Bernard, M.: Galería biográfica de artistas españoles del siglo XIX, Madrid, 1883-1884, p. 527; Arias Anglés, E.: Op. cit. nota 11, p. 263, núm. 183.

${ }^{47}$ Ossorio y Bernard, M.: Op. cit. nota 46, p. 527; Arias Anglés, E.: Op. cit. nota 11, p. 256, núm. 165.

48 Arias Anglés, E.: Op. cit. nota 11, p. 277, núm. 244.

${ }^{49}$ Arias Anglés, E.: Op. cit. nota 11, p. 256, núm. 165.

${ }^{50}$ Catálogo de los cuadros y esculturas pertenecientes á la galería de SS.AA.RR. los Serenísimos Infantes de España, Duques de Montpensier, Sevilla, 1866, p. 58, núm. 265. 

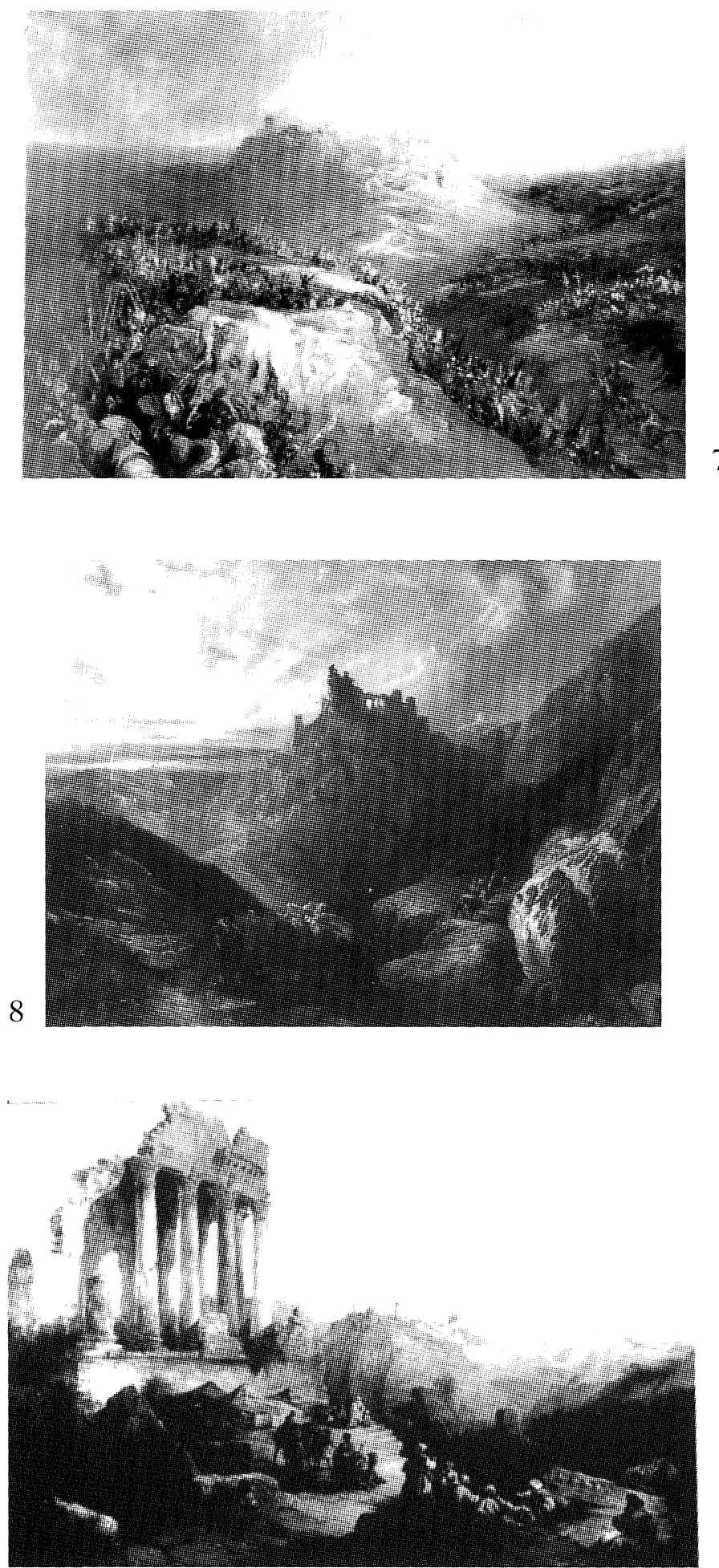

Figura 7. Jenaro Pérez Villaamil (tradicionalmente atribuido a Lucas). Los cruzados descubriendo la ciudad de Jerusalem. Fundación Lázaro Galdiano. Madrid.

Figura 8. Jenaro Pérez Villaamil. Las gargantas de las Alpujarras. Fundación Santa Marca. Madrid.

Figura 9. Jenaro Pérez Villaamil. Ruinas en las inmediaciones de Jerusalem. Patrimonio Nacional. Madrid. 
do la ciudad de Jerusalem, viniendo a concordar así los análisis técnico, formal e histórico que de la obra hemos hecho en que se trata de un cuadro de Pérez Villaamil y no de Lucas, como se le ha tenido hasta el presente. Eso si, no creemos que sea la obra definitiva que estuvo en la colección Montpensier, sino que más bien sea una especie de versión preparatoria y más abocetada de la misma.

Queda, pues, así expuesta, analizada y clarificada la producción orientalista de Lucas (tanto segura como atribuida) realizada bajo el influjo de la de Pérez Villaamil. Pero no se limitó dicha producción solamente a la citada influencia, sino que también Lucas realizó cuadros orientalistas dentro de su propio estilo y próximos al costumbrismo, su más característico género. Tal sería el caso de dos cuadros con asuntos referentes a la conversión de moros, situados en más o menos obscuros interiores de iglesias, y que, como en muchos de sus temas costumbristas, son las figuras las que adquieren fundamental relieve dentro de una composición en que el enmarque de interior queda, a veces, insinuado por medio de las penumbras. El caso más característico de ésto está representado por el cuadro titulado Conversión de moros —o El paganismo - (colección particular) ${ }^{51}$, firmado y fechado en 1861, donde, en el obscuro interior de un templo, sugerido a través de la penumbra, se ve la deshecha figura de un obispo o abad mitrado sobre un estrado, rodeado de personajes orientales con turbantes, uno de los cuales se postra a sus piés. Es obra, pues, dentro de lo que tradicionalmente se tiene por el más puro estilo luqueño, concebido con esa técnica manchista, deshecha, de veta brava, en que los toques de colores cálidos resaltan sobre los fondos de penumbras. El otro de estos dos cuadros que tratamos, se conserva en la Fundación Lázaro Galdiano bajo el título de Sermón a los moros ${ }^{52}$, obra sin firma ni fecha y de temática muy similar a la anterior, representando a un dominico predicando desde un púlpito a personajes musulmanes que se agrupan en el interior de una iglesia gótica y que, según sugiere Du Gué Trapier ${ }^{53}$, pudiera tratarse de San Vicente Ferrer exhortando a los moriscos en la iglesia de Santiago del Arrabal de Toledo. Es obra muy acabada en relación con el carácter abocetado de la otra, si bien no deja de acusarse lo suelto de la factura en lo que respecta a las figuras, especialmente en sus vestimentas y turbantes, recordándonos algunas de ellas, en su tratamiento y posturas, a las del cuadro anterior. Y aún citaríamos, dentro de esta acepción más puramente luqueña y costumbrista, el gouache titulado Moros alrededor del fuego ${ }^{54}$, del British Museum de Londres, que a pesar de que Du Gué Trapier quiere ver en él remembranzas delacroixianas ${ }^{55}$, nosotros encontramos más bien ecos compositivos y del expresionismo goyescos en ese abigarrado, achaparrado y misterioso grupo nocturno; e igualmente mencionaremos aquí, pero con ciertas reservas por sernos desconocidas, las dos versiones de Moros naufragos (Shipwrecked) mencionadas por Du Gué Trapier, una que perteneció a las galerías Demotte y la otra, firmada y fechada en 1863, a las Heinemann Galleries, obras en las que la citada autora encuentra reminiscencias de los románticos franceses ${ }^{56}$.

Y, por último, nos resta aún citar, dentro de esta producción orientalista de carácter costumbrista de Lucas, los dos célebres cuadros de la Fundación Lázaro Galdiano titulados Corriendo la pólvora (fig. 10) y Moros de Tetuán ${ }^{57}$ (fig. 11). Pero, se da otra vez el caso de

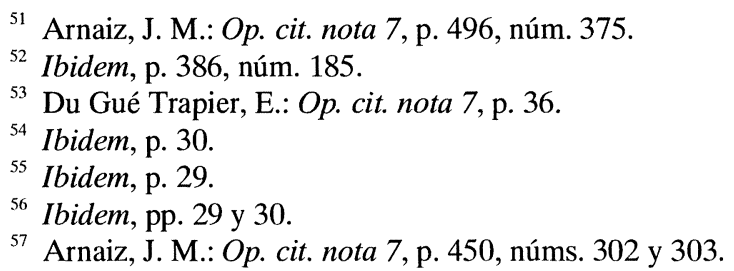


que, al no poseer ninguno ni firma ni fecha, en diversas ocasiones, también se han planteado dudas sobre su atribución, al igual que sucedía con el cuadro de Los cruzados. ¿Son realmente de Lucas estas obras? Los dos cuadros se despegan totalmente de la producción orientalista de Lucas, ya sea de la mayoritaria de carácter paisajista y cercana a Villaamil, como de la de tipo costumbrista, lo que ha hecho que las sospechas vengan de lejos y se hayan ido acentuando en el discurrir historiográfico del problema, cuya secuencia a continuación exponemos: 1ํ) En 1940 Du Gué Trapier resaltó la total diferencia de técnica existente entre dicha producción paisajistico-orientalista de Lucas y estos dos cuadros, puntualizando, además, que evocaban la influencia de Delacroix ${ }^{58} .2^{\mathbf{9}}$ ) En 1948 Gaya Nuño dice con respecto a Corriendo la pólvora (fig. 10) que «por su fuga, más coincidente que con Fortuny con el admirable Lameyer, es la obra más cercana a Delacroix de nuestro Lucas. Tiene de Delacroix un afán de elevación y galope que ha sido muy raro en nuestra pintura, que sólo se da, y no siempre, en Lameyer después del barroco» ${ }^{59}$; extrañado ante la elevación delacroixiana del cuadro, no puede por menos que conpararla con la horizontalidad dominante en Lucas y Alenza, quienes llegaron a crear una estética de lo achaparrado ${ }^{60}$. Ante esta contradicción, ante este apartamiento de los patrones que dominaron en la pintura de Lucas, y obligado a aceptar lo que para él es una paradójica realidad, no le queda más salida que decir que Marruecos elevó momentaneamente la visión de Lucas ${ }^{61}$; explicación que, desde luego, no nos convence, no sólo por no estar probado un viaje del pintor a Marruecos, sino además por resultarnos un tanto simplista para justificar el contrasentido de este par de obras en la producción luqueña, pareciéndonos, por el contrario, de lo más significativa esa llamada de atención, esa coincidencia con Lameyer que encuentra en la obra citada. 3º En 1973 GarcíaHerraiz pone de manifiesto el estrecho parentesco de estas dos obras con otras de Lameyer - especialmente Combate de moros (fig. 14), Museo del Prado-, pensando puedan ser debidas las tres a la mano de este ultimo pintor, por su común aire delacroixiano, similitud de estilo de los tres cuadros, pareja calidad de los amarillos y rojos de las capas, la manera de representar las nerviosas cabezas de los caballos de narices hinchadas y sentido vertical de la composición (espingardas en alto) ${ }^{62}$. 4º ) En 1992 Capelastegui, comparandolos con las obras de Lameyer Tipos marroquies ${ }^{63}$ de paradero desconocido (fig. 12), Zambra morisca ${ }^{64}$ del Museo del Prado (fig. 13), y Combate de moros ${ }^{65}$ del Museo del Prado (fig. 14), constata la afinidad en los trazos nerviosos y en las calidades cromáticas; la común estética vertical delacroixiana, lejana al achaparramiento luquense; la similitud de posturas, situaciones y encuadre entre el grupo de personajes del lateral izquierdo de Moros de Tetuán de la Fundación Lázaro Galdiano (fig. 11), atribuido a Lucas, y el de Tipos marroquíes de paradero desconocido (fig. 12), de Lameyer, así como de Zambra morisca del Museo del Prado (fig. 13), también de Lameyer, aunque aquí con encuadre frontal, estando los tres grupos de personajes de dichos cuadros sentados en un banco al pie del que han dejado sus babuchas, pero, además, llevando una espingarda el personaje que se haya sentado al extremo izquierdo del banco, tan-

${ }^{58}$ Du Gué Trapier, E.: Op. cit. nota 7, p. 29.

${ }^{59}$ Gaya Nuño, J. A.: Op. cit. nota 7, p. 21.

${ }^{60}$ Ibidem.

${ }^{61}$ Ibidem.

${ }^{62}$ García-Herraiz, E.: Op. cit. nota 37, pp. 349 y 350.

${ }^{63}$ Este cuadro es reproducido por Lago, S.: «Artistas de ayer.- Francisco Lameyer», La Esfera, año IX, núm. 449, 12 de agosto de 1922, de donde lo toma la citada autora.

${ }^{64}$ Puente, J. de la: Museo del Prado. Casón del Buen Retiro.-Catálogo de las pinturas del siglo XIX, Madrid, 1985, p. 115, núm. 4394 (con el título de Interior con moros. Reproducido).

${ }^{65}$ Ibidem, p. 116, núm. 4395 (reproducido). 

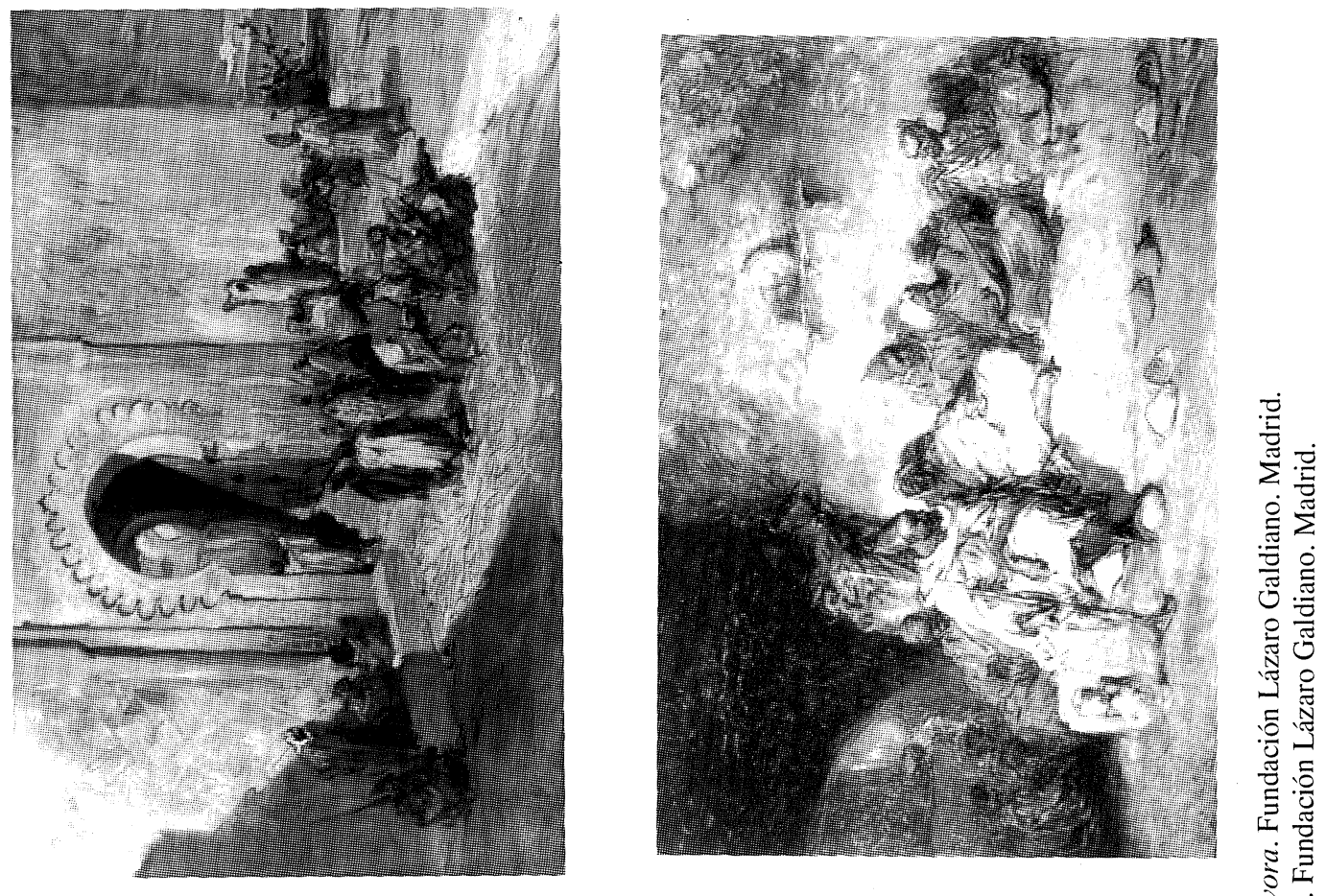

\section{운}

\section{N}
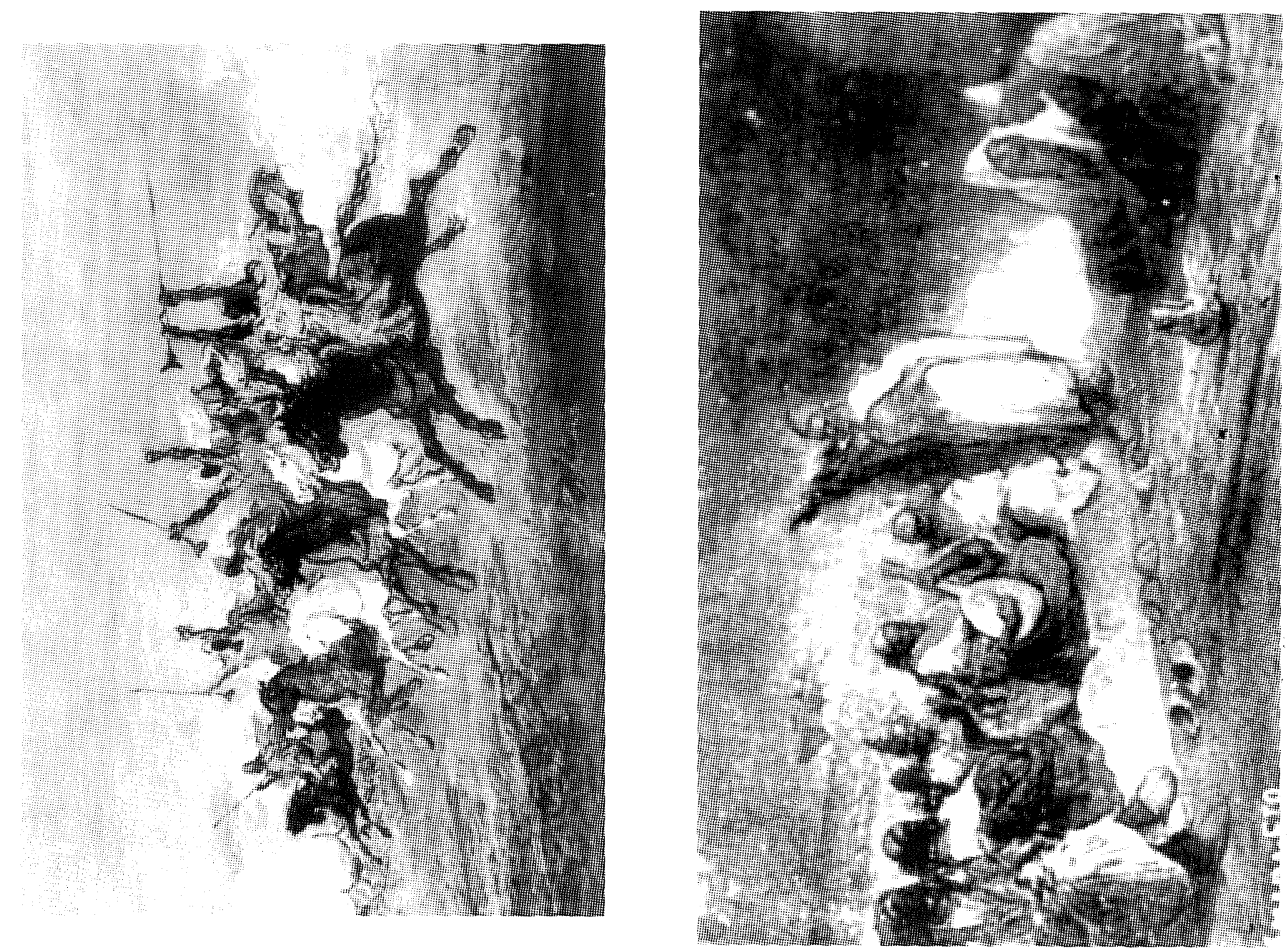

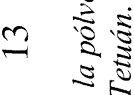

¿

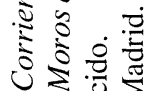

iิ

苋芯

용요 웡

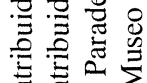

苋芯芯

豞苛

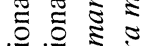

:⿹

苞导念

芯㝴

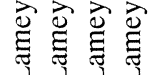

8000

㻤

$\dot{0}=\dot{2} \dot{2}$

苛苛苛苛 
to en el cuadro de Lameyer del Museo del Prado, como en el atribuido a Lucas de la Fundación Lázaro Galdiano; la similitud en las espingardas alzadas y la nerviosa factura de los sofocados caballos de Corriendo la pólvora de la Fundación Lázaro Galdiano (fig. 10), atribuido a Lucas, y Combate de moros del Museo del Prado (fig. 14), de Lameyer; la aparición en estos cinco lienzos de personajes negroides tocados con puntiagudos gorros rojos, característica de los negros «bukaras»-que nosotros también constatamos en Faquir en una mezquita de Tánger ${ }^{66} \mathrm{de}$ Lameyer, del Museo de Arte Contemporáneo de Lisboa (fig. 15)-; además de las comunes calidades cromáticas en todos ellos, como el rojo de los tocados y las manchas amarillas que van enrojeciéndose pasando por tonalidades anaranjadas, que colorean las babuchas de Zambra morisca del Museo del Prado (fig. 13), Combate de moros del mismo museo (fig. 14), ambos de Lameyer, y Moros de Tetuán de la Fundación Lázaro Galdiano (fig. 11), atribuido a Lucas ${ }^{67}$.

Sin embargo, y a pesar de aportar nuevos argumentos a los ya aducidos por Gaya Nuño y García-Herraiz, que nos inclinan aún más dichas obras hacia la autoría de Lameyer, la citada investigadora concluye su razonamiento diciéndonos que, a pesar de la semejanza formal y cromática que la tentaría a un cambio de atribución, la para ella diferente ejecución de los cuadros de la Fundación Lázaro, desdibujados, abocetados con esa mancha rápida y empastada que caracteriza la obra de Lucas, el uso de la espátula y el dinamismo de los personajes, que se enfrenta al espacio sosegado y parsimonioso de otras obras de Lameyer, todo ello la lleva a inferir que son cuadros de Lucas imitando la obra de ese pintor, recurriendo para ello, una vez más, a las aptitudes «camaleónicas» de Lucas, a su capacidad mimética con respecto a la obra de otros pintores, aplicada en este caso también a Lameyer, fechando dichos cuadros a partir de $1863{ }^{68}$, año en el que Lameyer regresó de su estancia en Marruecos entre 1862-1863 y supuestamente Lucas pudo haber conocido su producción orientalista.

Respetamos la opinión de la citada autora, pero nos cuesta comprender el que finalmente adjudique los dos cuadros a Lucas, tras haber aducido argumentos sólidos y suficientes para poder cambiar su atribución a Lameyer; ya que no entendemos su alusión a esa diferente ejecución en los cuadros de la Fundación Lázaro Galdiano, cuando antes señala la afinidad en los trazos nerviosos entre estas obras y las de Lameyer con que las compara; y más cuando esa técnica abocetada, desdibujada y manchista, está también presente, más o menos acusadamente, en la obra de Lameyer en general, y particularmente en uno de los cuadros que compara con los de la Fundación Lázaro Galdiano, el titulado Combate de moros del Museo del Prado (fig. 14), cuya fogosa ejecución, su técnica abocetada, manchista y nerviosa es de lo más semejante a la de Corriendo la pólvora de la Fundación Lázaro Galdiano (fig. 10); calidades técnicas, por otra parte, ya señaladas por Lafuente Ferrari en Lameyer cuando lo tilda de «genial bocetista» ${ }^{69}$ y califica de «fogosa ejecución» la de su cuadro Combate de moros del Museo del Prado ${ }^{70}$ (fig. 14), al igual que Santos Torroella, quien, tras considerar a Lameyer como el único fiel seguidor en nuestro país de Delacroix, puntualiza «La brillantez del colorido, el desgarro de la pincelada y el especial nerviosismo de la factura, que infunde ritmos de una vivacidad inusitada a ambas obras» ${ }^{71}$, refiriéndose a Zambra morisca (fig. 13)

\footnotetext{
${ }^{66}$ Reproducido primeramente por Lago, S.: Op. cit. nota 63 y posteriormente por Gaya Nuño, J. A.: Arte del siglo XIX, Ars Hispaniae, vol. décimonono, Madrid, 1966, p. 241, fig. 246.

${ }^{67}$ Capelastegui, P.: «El tema marroquí: Lameyer y Lucas», Archivo Español de Arte, t. LXV, núm. 257, 1992, p. 116.

${ }^{68}$ Ibidem, pp. 116 y 119.

${ }^{69}$ Lafuente Ferrari, E.: Breve historia de la pintura española, cuarta edición, Madrid, 1953, p. 454.

${ }^{70}$ Ibidem.

${ }^{71}$ Santos Torroella, R.: «Alenza, Lucas, Lameyer», Goya, núm. 104, 1971, p. 83
} 


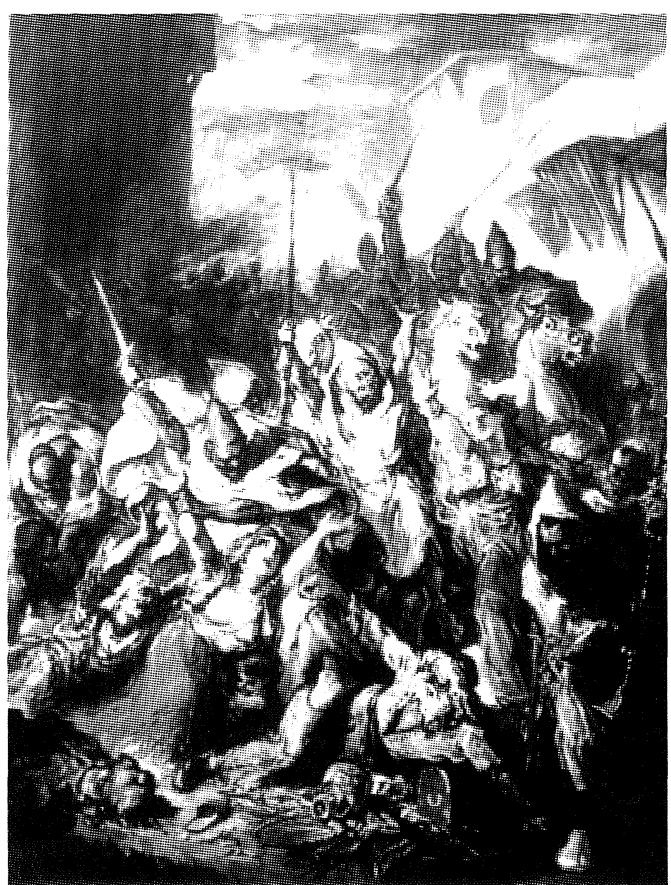

14

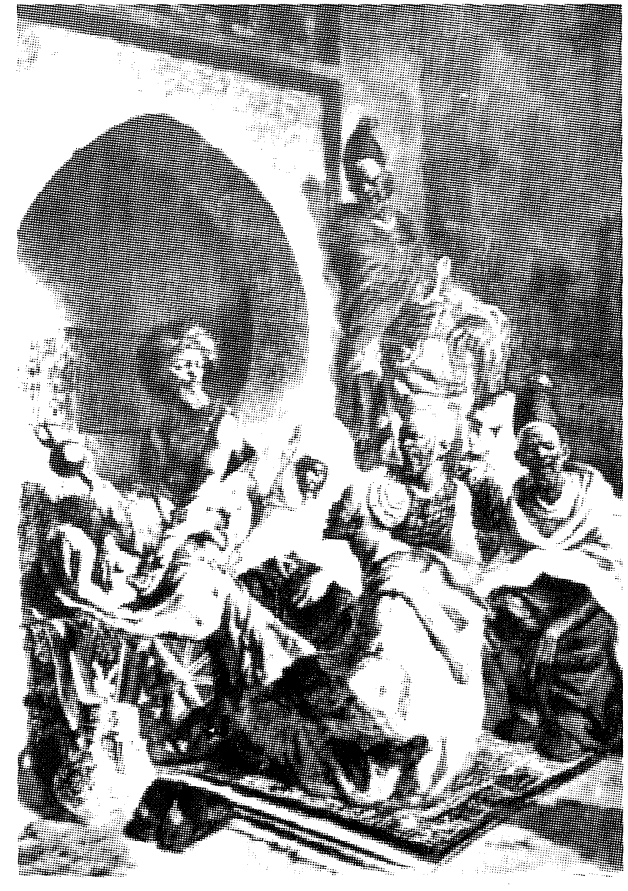

15

Figura 14. Francisco Lameyer. Combate de moros. Museo del Prado. Madrid.

Figura 15. Francisco Lameyer. Faquir en una mezquita de Tánger. Museo de Arte Contemporáneo. Lisboa.

y Combate de Moros (fig. 14), ambos del Museo del Prado. Pero, además, la alusión que hace dicha autora - sin duda pensando en Corriendo la pólvora de la Fundación Lázaro Galdiano (fig. 10) - al dinamismo, a la violenta irrupción de los personajes que se enfrenta al espacio sosegado y parsimonioso de otras obras de Lameyer, para adjudicar los dos cuadros a Lucas, tampoco nos parece concluyente, cuando, por un lado, dichas dinámicas características están también presentes en el citado cuadro de Lameyer Combate de moros del Museo del Prado (fig. 14) y, por el otro, Moros de Tetuán de la Fundación Lázaro Galdiano (fig. 11), al que supone de Lucas, participa precisamente de ese espacio sosegado y parsimonioso que atribuye a las obras de Lameyer. Sin olvidar que no todo en la obra de Lucas posee ese citado dinamismo, como tampoco es todo sosiego y parsimonia en la de Lameyer, como así lo vió acertadamente Lafuente Ferrari cuando nos dice que fue «pintor de ejecución fogosa o apurada, según convenía a su intención» ${ }^{72}$.

Pero, además, que por ahora sepamos, Lucas no estuvo en Marruecos, pues la alusión que se viene haciendo a los dos gouaches de puertos morunos, dedicados a Don Ángel Pozas en 1859, que antes citamos, como posible prueba de dicho viaje, desde que para ello los utilizara Du Gué Trapier en 1940, carece de cualquier valor documental, como bien ha probado Capelastegui ${ }^{73}$. Ello se debe a que entonces estos eran los cuadros orientalistas de fecha más temprana que se conocían de Lucas, y además coincidente con la guerra de Marruecos, lo que bastó para pensar que pudieran servir para datar un posible viaje del pintor a

\footnotetext{
${ }^{72}$ Lafuente Ferrari, E.: Op. cit. nota 69, p. 454.

${ }^{73}$ Capelastegui, P.: Op. cit. nota 67, pp. 118 y 119.
} 
Marruecos que justificase también otras obras orientalistas posteriores. Pero se da el caso de que hoy conocemos obras orientalistas de Lucas fechadas anteriormente a éstas, según ya hemos visto. Y, además, todas ellas, como la mayoría de la producción orientalista de Lucas conocida, son paisajitos orientales de una gran convencionalidad, insuficientes para probar - o tan siquiera suponer - una estancia del pintor en Marruecos, como bien lo vió y expuso Capelastegui ${ }^{74}$. Por otro lado, volviendo a los dos discutidos cuadros de la Fundación Lázaro Galdiano, si el titulado Corriendo la pólvora (fig. 10) pude obedecer tanto a la remenbranza de algo visto en la realidad como a la fantasía del autor quizá ayudada por la contemplación de algún grabado, Moros de Tetuán (fig. 11), debido a su temática y encuadre, parece claramente corresponderse con un boceto tomado directamente del natural. Y si Lucas no estuvo nunca en Marruecos, Lameyer si que lo estuvo, concretamente, como ya hemos dicho, en 1862-1863, coincidiendo allí con Fortuny ${ }^{75}$. Pero además, los patentes ecos de Delacroix que detentan las citadas dos obras de la Fundación Lázaro Galdiano, sólo pueden ser debidos a un directo conocimiento de la obra del romántico francés y, que sepamos, tampoco está documentado un viaje de Lucas a París. Se piensa, simplemente, para justificar el influjo delacroixiano en estos dos cuadros, que quizá lo pudiera realizar con motivo de la Exposición Universal de París de 1855, donde expuso, con éxito de crítica, un par de obras suyas; o por su supuesta amistad con Manet, cuya Lola de Valencia, fechada en 1862, en opinión de Aureliano de Beruete era obra de colaboración de los dos artistas; o el que a decir de Lázaro Galdiano realizó para deshacer un equívoco surgido respecto a un boceto suyo de tipo velazqueño ${ }^{76}$. En una palabra, todo ello simples conjeturas o rumores sin apoyo documental alguno. Sin embargo Lameyer tuvo largas estancias en París y Burdeos, donde facilmente pudo conocer y sentir la fascinación por el arte de Delacroix, la asimilación de su tipo de pintura, especialmente la de carácter orientalista, que coincidía con sus gustos exóticos, despertados por sus viajes a Marruecos, Argelia, Egipto y Oriente Medio.

Por todo ello pensamos que los dos tan traidos y llevados cuadros de la Fundación Lázaro Galdiano, Corriendo la pólvora (fig. 10) y Moros de Tetuán (fig. 11), han de ser adjudicados a Lameyer, significativamente el único pintor orientalista delacroixiano de nuestro romanticismo; participando plenamente dichos cuadros de las características generales que dominan en su producción de este tipo, las de un orientalismo costumbrista de influjo francés que vino a sustituir y a reavivar al ya un tanto añejo orientalismo paisajista de influencia británica introducido por Pérez Villaamil y continuado, con más acusados rasgos raciales, por su amigo Lucas. Esto, como decimos, está patente en toda la producción orientalista de Lameyer, donde la figura se adelanta hacia los primeros términos, adquiriendo mayor relevancia en relación con el encuadre, dando así pleno protagonismo a la anécdota, frente a lo diluido de la misma en las alejadas visiones paisajísticas, pobladas de personajillos, de Pérez Villaamil y Lucas, donde las ruinas y arquitecturas poseen gran significación, ya respondiendo a un cierto deseo de definición de un historicismo nacional, caso del primero, ya por puro mimetismo y anhelo de fantasía decorativa, caso del segundo. Así, la mayor o menor proximidad de las figuras al plano de encuadre determina también la factura más deshecha o más acabada del cuadro, en consonancia también con lo dinámico o apacible del asunto tratado, en perfecta concordancia con las palabras de Lafuente Ferrari sobre Lameyer antes reproducidas: «pintor de ejecución fogosa o apurada, según convenía a su intención» ${ }^{77}$.

\footnotetext{
${ }^{74}$ Ibidem.

${ }^{75}$ Ibidem, p. 113.

${ }^{76}$ Arnaiz, J. M.: op. cit. nota 7, p. 33.

77 Vid. nota 72.
} 
Por lo demás, la obra de Lameyer responde a todos lo tópicos iconográficos que generó el orientalismo internacional. Las escenas de moros descansando o tocando música, representadas por Zambra morisca del Museo del Prado (fig. 13), Tipos marroquíes de paradero desconocido (fig. 12) y Moros de Tetuán de la Fundación Lázaro Galdiano (fig. 11); el salvaje y festivo rito de Corriendo la pólvora de la Fundación Lázaro Galdiano (fig. 10); la violencia y la crueldad, unida a los personajes negros como símbolos de la muerte, en Combate de moros del Museo del Prado (fig. 14), título que no responde al real asunto del cuadro, que representa el sangriento asalto de negros «bukaras» a una judería; el exotismo mistico-religioso de los santones o fakires, no exento de cierto misterio, en Fakir en una mezquita de Tánger del Museo de Arte Contemporáneo de Lisboa (fig. 15); las escenas y mujeres judías, que vinieron muchas veces a sustituir, por su lógica dificultad, a las representaciones de mujeres moras, patente en Mujeres judías de Tánger (o Mendigo de Tánger) del Museo de Arte Contemporáneo de Lisboa y Judía argelina de paradero desconocido; el desierto y el mundo de los beduinos, últimos hombres libres que, para preservar su libertad, tuvieron que seguir el camino de la desolación, según la visión de los románticos, representado por Viajeros en el desierto del Museo Romántico de Madrid; la sensualidad, manifestada en su Odalisca de paradero desconocido; o los asuntos históricos, como La batalla de Uclés bajo Alfonso VI de paradero desconocido. Un repertorio, pues, de plenas resonancias delacroixianas y en consonancia total con lo que el orientalismo internacional establecía para este género en Europa, cosa que sólo un pintor que hubiera estado largas temporadas en Francia podía abordar y representar en esos momentos en España. 